\title{
Light inhibition of the conversion of 1-aminocyclopropane-1-carboxylic acid to ethylene in leaves is mediated through carbon dioxide
}

\author{
Ching Huei Kao* and Shang Fa Yang \\ Department of Vegetable Crops, University of California, Davis, CA 95616, USA
}

\begin{abstract}
The mechanism of light-inhibited ethylene production in excised rice (Oryza sativa L.) and tobacco (Nicotiana tabacum L.) leaves was examined. In segments of rice leaves light substantially inhibited the endogenous ethylene production, but when $\mathrm{CO}_{2}$ was added into the incubation flask, the rate of endogenous ethylene production in the light increased markedly, to a level which was even higher than that produced in the dark. Carbon dioxide, however, had no appreciable effect of leaf segments incubated in the dark. The endogenous level of 1-aminocyclopropane-1-carboxylic acid (ACC), the immediate precursor of ethylene, was not significantly affected by lightdark or $\mathrm{CO}_{2}$ treatment, indicating that dark treatment or $\mathrm{CO}_{2}$ exerted its effect by promoting the conversion of ACC to ethylene. This conclusion was supported by the observations that the rate of conversion of exogenously applied ACC to ethylene was similarly inhibited by light, and this inhibition was relieved in the presence of $\mathrm{CO}_{2}$. Similar results were obtained with tobacco leaf discs. The concentrations of $\mathrm{CO}_{2}$ giving half-maximal activity was about $0.06 \%$, which was only slightly above the ambient level of $0.03 \%$. The modulation of ACC conversion to ethylene by $\mathrm{CO}_{2}$ or light in detached leaves of both rice and tobacco was rapid and fully reversible, indicating that $\mathrm{CO}_{2}$ regulates the activity, but not the synthesis, of the enzyme converting ACC to ethylene. Our results indicate that light inhibition of ethylene production in detached leaves is mediated through the internal level
\end{abstract}

\footnotetext{
* Permanent address: Department of Agronomy, National Taiwan University, Taipei, Taiwan, Republic of China Recipient of a Republic of China National Science Council Fellowship
}

Abbreviation: $\mathrm{ACC}=1$-aminocyclopropane-1-carboxylic acid of $\mathrm{CO}_{2}$, which directly modulates the activity of the enzyme converting $\mathrm{ACC}$ to ethylene.

Key words: 1-Aminocyclopropane-1-carboxylic acid - Carbon dioxide and $\mathrm{C}_{2} \mathrm{H}_{4}$ production - Ethylene production - Light and $\mathrm{C}_{2} \mathrm{H}_{4}$ production Nicotiana-Oryza.

\section{Introduction}

Depending on the tissue involved, light can promote (Craker et al. 1973; Saltveit and Pharr 1980) or inhibit (Goeschl et al. 1967; Kang and Burg 1972; Samimy 1978) ethylene production. Carbon dioxide has also been reported to promote or inhibit ethylene production in various tissues (Aharoni and Lieberman 1979; Young et al. 1962). Recently Gepstein and Thimann (1980), de Laat et al. (1981) and Grodzinski et al. (1981) reported that light markedly inhibited the conversion of 1-aminocyclopropane-1-carboxylic acid (ACC), the immediate precursor of ethylene in plant tissues (Adams and Yang 1979), into ethylene by various leaf tissues. Gepstein and Thimann (1980) suggested that light exerted its inhibitory effect by oxidation of essential SH group(s) of the enzyme system converting ACC to ethylene. De Laat et al. (1981) proposed that light regulated both synthesis and activation of the ACC-converting enzyme in leaves. Most recently, Wright (1981) also found that light substantially inhibited the production of ethylene induced by water stress in detached wheat leaves and in leaves on the intact plant. He concluded that either the biosynthesis of $\mathrm{ACC}$ or the conversion of $\mathrm{ACC}$ to ethylene required an obligatory dark stage. In these studies the leaf tissues were incubated in enclosed containers under light 
or dark conditions, where the concentration of carbon dioxide decreased or increased because of $\mathrm{CO}_{2}$ fixation by photosynthesis or $\mathrm{CO}_{2}$ production by respiration. Since $\mathrm{CO}_{2}$ is known to promote ethylene production rates in detached leaves (Aharoni and Lieberman 1979; Gepstein and Thimann 1981) and intact plants (Dhawn et al. 1981), the inhibition of ethylene production by light may result from a decrease in internal $\mathrm{CO}_{2}$ concentration. In this communication we present data showing that light inhibition of ACC-dependent ethylene production in leaves is indeed mediated through $\mathrm{CO}_{2}$.

\section{Materials and methods}

Plant materials. Rice (Oryza sativa L. cv. Taichung Native 1) seeds obtained from Taiwan were sterilized with sodium hypochlorite solution $(0.5 \%)$ for $5 \mathrm{~min}$, rinsed with deionized water, and soaked for $48 \mathrm{~h}$ in the dark at $30^{\circ} \mathrm{C}$. Uniformly germinated seeds were then grown in vermiculite for 8-9 d at $30^{\circ} \mathrm{C}$ under continuous white light $\left(80 \mu \mathrm{mol}\right.$ quanta $\left.\mathrm{m}^{-2} \mathrm{~s}^{-1}\right)$. The seedlings were watered with half-concentration Johnson's modified nutrient solution (Johnson et al. 1957), $\mathrm{pH}$ 4.5. The solution was replaced every $3 \mathrm{~d}$. Tobacco plants (Nicotiana tabacum L. cv. Havana 425; seeds kindly provided by Department of Plant Pathology, University of California, Davis) were grown in a greenhouse under natural light and a temperature of no less than $20^{\circ} \mathrm{C}$. Fully grown leaves of 11 -week-old plants were used for the experiments.

Incubation conditions. Ten rice leaf segments (the apical $3 \mathrm{~cm}$ of the third leaves), weighing about $50 \mathrm{mg}$, or seven tobacco leaf discs ( $1 \mathrm{~cm}$ diameter), weighing about $150 \mathrm{mg}$, were floated on 10 and $1 \mathrm{ml}$, respectively, of test solution in a 50 -ml flask. The flasks were flushed with air, sealed with rubber serum caps, and incubated at $30^{\circ} \mathrm{C}$ either under light $(80 \mu \mathrm{mol}$ quanta $\mathrm{m}^{-2} \mathrm{~s}^{-1}$ ) provided by a mixture of cool-white and Grolux tubes, or in darkness. For the experiments in which various concentrations of $\mathrm{CO}_{2}$ were used, all flasks were flushed with $\mathrm{CO}_{2}$-free air and sealed. To obtain desired concentrations of $\mathrm{CO}_{2}$, a known amount of $\mathrm{CO}_{2}$ was injected into each sealed flask; a $\mathrm{CO}_{2}$-free ("minus $\mathrm{CO}_{2}$ ") atmosphere was achieved by hanging in the flask a center well containing a filter paper wick wetted with $0.2 \mathrm{ml}$ of $20 \% \mathrm{KOH}$. The concentrations of $\mathrm{CO}_{2}$ in the flasks were determined with a gas chromatograph (Model 800; Carle Instruments, Fullerton, Cal. USA) equipped with a Silica-gel column and a thermoconductivity detector. After each determination of ethylene, the flasks were flushed with fresh air or $\mathrm{CO}_{2}$-free air as described and when required, $\mathrm{CO}_{2}$ was reintroduced. The $\mathrm{CO}_{2}$ concentration in the $\mathrm{CO}_{2}$-free air treatment was below $0.01 \%$.

Determination of ethylene. A 1-ml gas sample was withdrawn from the head space of the flask with a hypodermic syringe, and ethylene was assayed using a gas chromatograph equipped with an alumina column and a flame ionization detector.

Determination of $A C C$. Rice leaf segments were extracted twice with boiling $80 \%$ ethanol. The ethanol was evaporated under vacuum at $40^{\circ} \mathrm{C}$. The residue was dissolved in $2 \mathrm{ml}$ of water and the pigments were removed by adding $0.5 \mathrm{ml}$ of chloroform. An aliquot of the aqueous solution was used for assay of ACC according to the method of Lizada and Yang (1979).

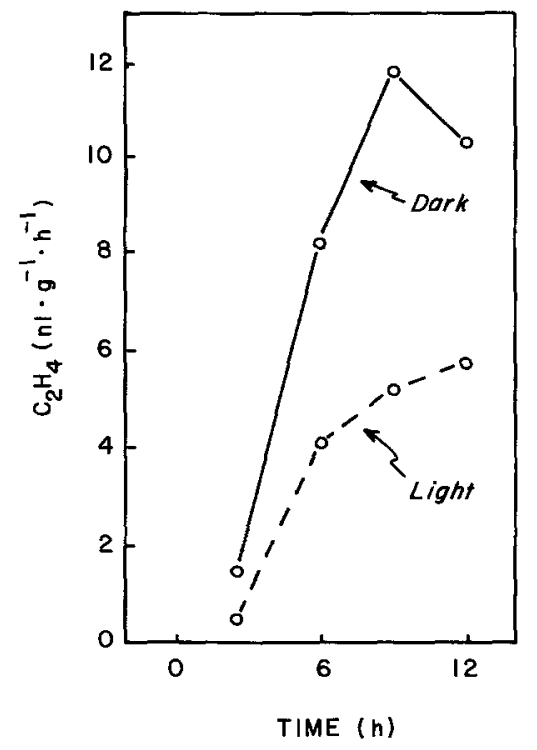

Fig. 1. Effects of light and darkness on the time course of ethylene production in rice leaf segments

The efficiency of the conversion of ACC to ethylene was between 65 and $70 \%$. The amount of ACC was calculated from the quantity of ethylene liberated and the conversion efficiency.

\section{Results}

Effects of light and $\mathrm{CO}_{2}$ on the basal ethylene production in rice leaves. The effects of light and darkness on the rate of endogenous ethylene production by excised rice leaf segments is shown in Fig. 1. Although the rates increased with time under light or darkness, it is clear that the ethylene production rates in the light were lower. The increase in ethylene production rates with time is probably a wound response. Since the experiment was carried out in sealed flasks, the concentration of $\mathrm{CO}_{2}$ in flasks under light would be lower than that under darkness, because of $\mathrm{CO}_{2}$ fixation by photosynthesis and possibly a reduction in $\mathrm{CO}_{2}$ production because of light inhibition of dark respiration (see e.g. Graham 1980). For example, when rice leaf segments were enclosed in a flask and incubated for $6 \mathrm{~h}$ under light conditions, $\mathrm{CO}_{2}$ concentration decreased from 0.08 to $0.01 \%$, whereas under dark conditions $\mathrm{CO}_{2}$ increased about five-fold from 0.08 to $0.39 \%$ (Table 1$)$.

In order to examine whether ethylene production rates were sensitive to $\mathrm{CO}_{2}$ concentrations, the effect of $\mathrm{CO}_{2}$ concentration on the endogenous ethylene production during the first 6-h incubation period under light was studied. The ethylene production rates were markedly influenced by the $\mathrm{CO}_{2}$ concentration. Ethylene production increased with increasing concentrations of $\mathrm{CO}_{2}$ and reached a 
Table 1. Effect of $\mathrm{CO}_{2}$ on basal and ACC-dependent ethylene production by rice leaf segments. Leaf segments were enclosed in flasks under air, $3 \% \mathrm{CO}_{2}$, or $\mathrm{CO}_{2}$-free air, and incubated in the presence or absence of $\mathrm{ACC}(1 \mathrm{mM})$ in the light or darkness. Ethylene production was assayed after $6 \mathrm{~h}$ incubation. The concentrations of $\mathrm{CO}_{2}$ in the air flasks at the beginning and at the end of incubation were 0.08 and $0.39 \%(\mathrm{v} / \mathrm{v})$, respectively, under darkness, and 0.08 and $0.01 \%$, respectively under light

\begin{tabular}{llc}
\hline Treatment & \multicolumn{2}{c}{$\mathrm{C}_{2} \mathrm{H}_{4}\left(\mathrm{nl} \mathrm{g}^{-1} 6 \mathrm{~h}^{-1}\right)$} \\
\cline { 2 - 3 } & $-\mathrm{ACC}$ & $+\mathrm{ACC}$ \\
\hline Darkness & & \\
$\quad \mathrm{Air}$ & 41 & 106 \\
$\mathrm{CO}_{2}(3 \%)$ & 35 & 111 \\
$\mathrm{CO}_{2}$-free air & 16 & 30 \\
Light & & \\
$\mathrm{Air}$ & 13 & 62 \\
$\mathrm{CO}_{2}(3 \%)$ & 71 & 237 \\
$\mathrm{CO}_{2}$-free air & 13 & 54 \\
\hline
\end{tabular}

Table 2. Effect of light-dark treatments or $\mathrm{CO}_{2}$ treatment on ethylene production and the endogenous ACC level in rice leaf segments. For Exp. I the leaf segments were incubated in the light or darkness for $6 \mathrm{~h}$ and ethylene accumulated during this period was determined. In Exp. II, the leaf segments were first incubated for $3 \mathrm{~h}$ in the light and then enclosed for $1 \mathrm{~h}$ under light in the $\mathrm{CO}_{2}$-free $\left(-\mathrm{CO}_{2}\right)$ or $3 \% \mathrm{CO}_{2}\left(+\mathrm{CO}_{2}\right)$ atmosphere. Ethylene accumulated during this $1 \mathrm{~h}$ period was determined. Immediately after ethylene determinations, the same samples were assayed for $\mathrm{ACC}$

\begin{tabular}{lll}
\hline Treatment & $\begin{array}{l}\mathrm{C}_{2} \mathrm{H}_{4} \\
\left(\mathrm{nl} \mathrm{g}^{-1} \mathrm{~h}^{-1}\right)\end{array}$ & $\begin{array}{l}\mathrm{ACC} \\
\left(\mathrm{nmol} \mathrm{g}^{-1}\right)\end{array}$ \\
\hline $\begin{array}{l}\text { Experiment I } \\
\quad \text { Light } \\
\quad \text { Darkness }\end{array}$ & 2.4 & 20.5 \\
$\begin{array}{l}\text { Experiment II } \\
\quad \mathrm{CO}_{2}\end{array}$ & 7.0 & 19.3 \\
$+\mathrm{CO}_{2}$ & & \\
\hline
\end{tabular}

plateau at about $2-3 \%$ of $\mathrm{CO}_{2}$ concentration (data not shown).

The effect of $3 \% \mathrm{CO}_{2}$ on ethylene production by rice leaf segments under light and darkness were compared. The results shown in Table 1 clearly indicate that the reduced ethylene-production rate in the ambient air under light as compared to that under darkness was the consequence of the limited $\mathrm{CO}_{2}$ concentration under the light treatment. This conclusion was based on observations that (a) $3 \%$ $\mathrm{CO}_{2}$ greatly enhanced the ethylene produced under light but had little effect under darkness, and (b) when $\mathrm{CO}_{2}$ was removed from the flasks, the ethylene produced under light was not affected, but that under dark was greatly reduced to a rate comparable to that under light. Since the air-filled flask

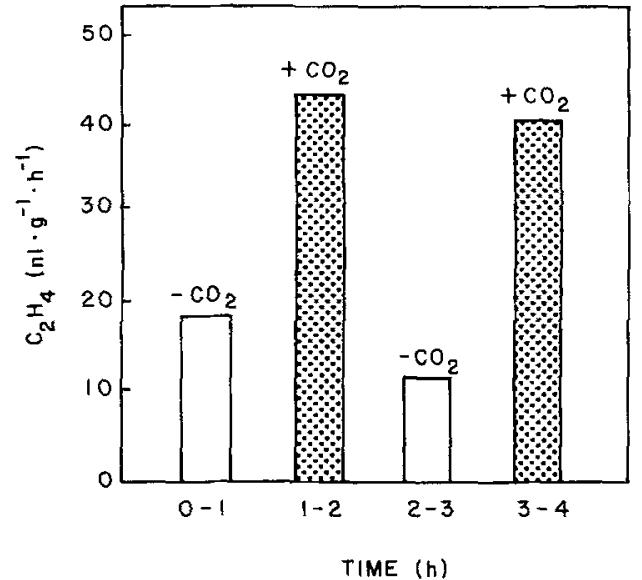

Fig. 2. Influence of plus- and minus- $\mathrm{CO}_{2}$ alternations on ACCdependent ethylene production in rice leaf segments. After leaf segments were preloaded with ACC ( $3 \mathrm{mM})$ for $3 \mathrm{~h}$ under light, they were enclosed in a flask and incubated alternately in $\mathrm{CO}_{2}$ free air (open bar) and $3 \% \mathrm{CO}_{2}$ (hatched bar) for $1 \mathrm{~h}$

under light contained $0.01 \%$ of $\mathrm{CO}_{2}$ at the end of incubation and as little ethylene had been produced as in the flask filled with $\mathrm{CO}_{2}$-free air, it may be assumed that $0.01 \% \mathrm{CO}_{2}$ was too low to stimulate appreciably ethylene production. Conversely, the air-filled flask under darkness contained $0.39 \% \mathrm{CO}_{2}$ at the end of incubation and as much ethylene had been produced as in the flask initially filled with $3 \% \mathrm{CO}_{2}$, indicating the $0.39 \%$ $\mathrm{CO}_{2}$ exerted maximal or nearly maximal activity.

Effects of light and $\mathrm{CO}_{2}$ on ACC-dependent ethylene production and the endogenous $A C C$ levels in rice leaves. Adams and Yang (1979) have studied ethylene biosynthesis in apple tissue and established the following pathway: methionine $\rightarrow$ S-adenosylmethionine $\rightarrow \mathrm{ACC} \rightarrow$ ethylene. Therefore, it would be interesting to determine at which step in the ethylene biosynthetic pathway $\mathrm{CO}_{2}$ exerts its promotive effect on ethylene production. The effects of light-dark or $\mathrm{CO}_{2}$ treatment on ethylene production rates and the endogenous $\mathrm{ACC}$ level in rice leaf segments was examined. Although dark treatment or $\mathrm{CO}_{2}$ treatment under light increased ehtylene production several-fold, these treatments did not change the internal levels of ACC appreciably (Table 2), indicating that dark condition or $\mathrm{CO}_{2}$ exerts its promotive effect mainly through enhancing the conversion of ACC to ethylene. When ACC was applied to rice leaf segments incubated in the light, ethylene production increased markedly with the increase in external ACC concentration up to at least $3 \mathrm{mM}$ (data not shown).

The conclusion that $\mathrm{CO}_{2}$ exerts its promotive effect through enhancing the conversion of $\mathrm{ACC}$ 


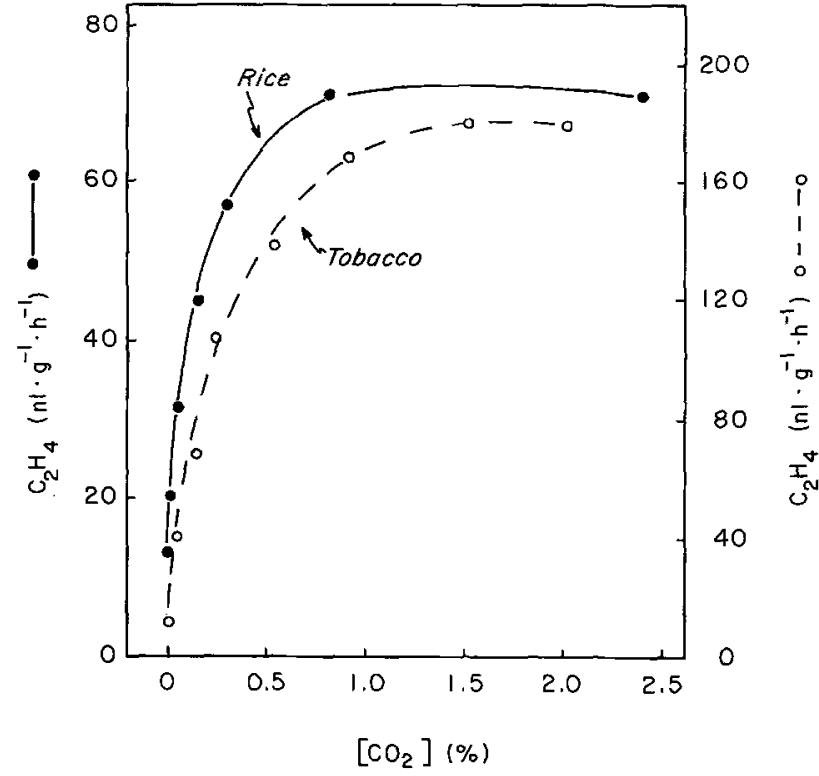

Fig. 3. Effect of $\mathrm{CO}_{2}$ concentration on ACC-dependent ethylene production in rice leaf segments and tobacco leaf discs. After leaf segments or discs were preloaded with ACC ( $3 \mathrm{mM}$ ) for $3 \mathrm{~h}$ in the light, they were enclosed in flasks containing various concentrations of $\mathrm{CO}_{2}$ and incubated for $1 \mathrm{~h}$ in the light. Ethylene was assayed after $1 \mathrm{~h}$ of $\mathrm{CO}_{2}$ treatment. The $\mathrm{CO}_{2}$ concentration indicated was the average of the $\mathrm{CO}_{2}$ concentrations present in the flask immediately before and after 1-h incubation

to ethylene was further supported by the observation that the ACC-dependent ethylene production in the light by rice leaf segments was also greatly stimulated by $\mathrm{CO}_{2}$ (Table 1). Similar to the basal ethylene production system (Table 1), light markedly inhibited ACC-dependent ethylene production under air, and the promotive effect of $\mathrm{CO}_{2}$ on ACC-dependent ethylene production was more pronounced under light than under darkness. Once an effective concentration of $\mathrm{CO}_{2}$ was provided, the rate of $A C C$-dependent ethylene production became greater in the light than in darkness, indicating that light per se did not inhibit but stimulates the conversion of $\mathrm{ACC}$ to ethylene.

The stimulation of ethylene production in the light by $\mathrm{CO}_{2}$ appeared to be readily reversible, as shown in Fig. 2. These data indicate that $\mathrm{CO}_{2}$ promotes the conversion of $\mathrm{ACC}$ to ethylene not by inducing the synthesis of the enzyme involved in the conversion but by activating the enzyme.

The dependence of ACC-dependent ethylene production on $\mathrm{CO}_{2}$ concentration under light was examined using rice leaf segments. The data in Fig. 3 show that ACC-dependent ethylene production increased as the $\mathrm{CO}_{2}$ concentration increased, and reached a maximal rate of $\mathrm{CO}_{2}$ concentration

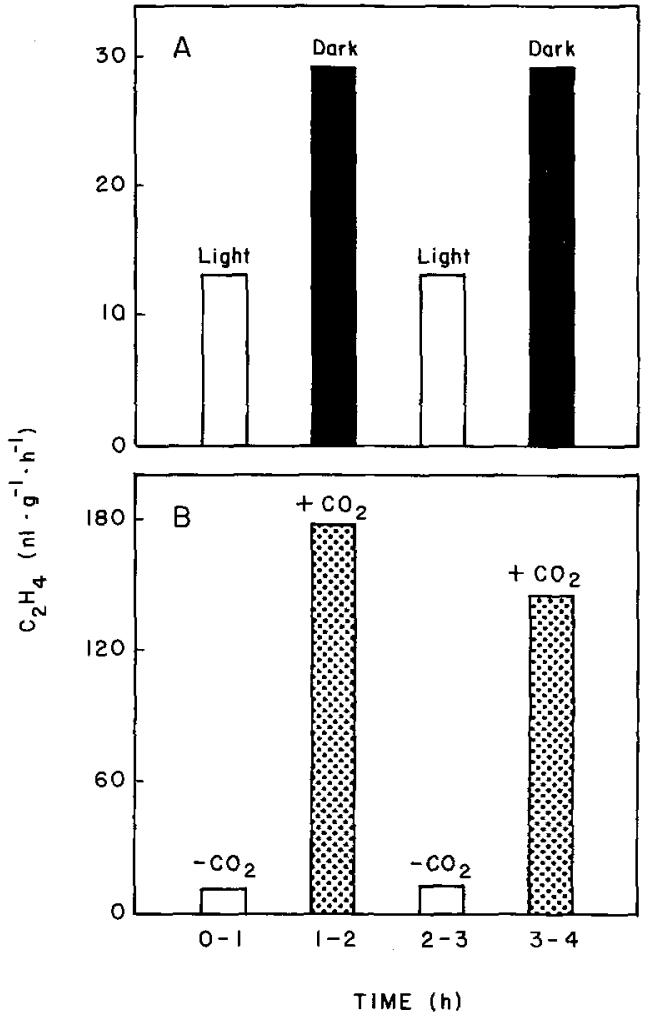

Fig. 4A, B. Effects of light-darkness alternations and minusand plus- $\mathrm{CO}_{2}$ alternations on ACC-dependent ethylene production in tobacco leaf discs. After leaf discs were preloaded with $\mathrm{ACC}(3 \mathrm{mM})$ for $3 \mathrm{~h}$ in the light, they were enclosed in a flask, A containing ambient air and incubated alternately under light and darkness for $1 \mathrm{~h}$ each, or $\mathbf{B}$ incubated alternately in the absence (with $\mathrm{KOH}$ solution) or presence of $2 \% \mathrm{CO}_{2}$ for $1 \mathrm{~h}$ each under light

of about $0.8 \%$; the half-maximal activity of $\mathrm{CO}_{2}$ was estimated to be about $0.06 \%$.

Effects of light and $\mathrm{CO}_{2}$ on $A C C$-dependent ethylene production in tobacco leaves. Since tobacco leaf discs were employed by both Gepstein and Thimann (1980) and de Laat et al. (1981) in their studies of the light inhibition of ACC conversion to ethylene, we have examined whether the light inhibition of ACC conversion to ethylene in tobacco leaf discs was also mediated through $\mathrm{CO}_{2}$. As in rice leaf segments ACC-dependent ethylene production rate in tobacco leaf discs was inhibited by light (Fig. $4 \mathrm{~A}$ ), but when $2 \% \mathrm{CO}_{2}$ was provided ethylene production was stimulated more than ten times (Fig. 4B). Furthermore this effect of $\mathrm{CO}_{2}$ on ACC-dependent ethylene production under light was fully reversible (Fig. 4B). The effect of $\mathrm{CO}_{2}$ concentration on ACC-dependent ethylene production by tobacco leaf discs is illustrated in Fig. 3. Carbon dioxide saturated the system at 
$1.5 \%$, and the half-maximal activity was obtained at $0.18 \% \mathrm{CO}_{2}$.

\section{Discussion}

Gepstein and Thimann (1980) were the first to report that light inhibited ACC-dependent ethylene production. Based on the observation in tobacco leaf discs that mercaptoethanol reversed the light inhibition of $\mathrm{ACC}$ conversion to ethylene, they suggested that light exerted its inhibitory effect by oxidizing the essential $\mathrm{SH}$ group(s) of the enzyme converting $\mathrm{ACC}$ to ethylene. This explanation was questioned by de Laat et al. (1981), who were not able to confirm the finding that mercaptoethanol reversed the light inhibition. Although no specific explanation was offered, de Laat et al. (1981) suggested that light inhibited ACC-converting enzymes at the level of both synthesis and activation.

Our present study clearly shows that light inhibits ethylene production by inhibiting the conversion of $\mathrm{ACC}$ to ethylene, and this inhibition is mediated through lowering the internal $\mathrm{CO}_{2}$ concentration. Since our results indicate that the effects of plus-minus- $\mathrm{CO}_{2}$ alternation and lightdark alternation are rapid and fully reversible (Figs. 2,4), it is most unlikely that $\mathrm{CO}_{2}$ or light regulates $\mathrm{ACC}$ conversion to ethylene at the level of synthesis of the enzyme. It is therefore suggested that the light effect is mediated through $\mathrm{CO}_{2}$ which in turn regulates ethylene production by activating the enzyme involved in the ACC conversion to ethylene. The inhibition of ACC conversion to ethylene by light appears to be a general phenomenon since this effect was observed in leaf tissue of both a monocotyledon (rice) and a dicotyledon (tobacco). It has been reported that dichlorophenyldimethylurea, an inhibitor of photosynthetic electron transport, countereacted the inhibitory action of light on ethylene production (de Laat et al. 1981; Grodzinski et al. 1981). Such results are in accord with our conclusion since this inhibitor would result in the accumulation of $\mathrm{CO}_{2}$ within the cell, and thereby relieve the inhibitory effect of light. Moreover, our conclusion explains well the previous observation that ACC-induced ethylene production was inhibited by light in green Pharbitis cotyledons but not in cotyledons that lacked chlorophyll (de Laat et al. 1981).

In the " $\mathrm{CO}_{2}$-free atmosphere" there always exists a very low but detectable concentration $(0.005-0.01 \%)$ of $\mathrm{CO}_{2}$ in the incubation tubes. It is therefore unlikely that the basal ethylene production in the " $\mathrm{CO}_{2}$-free" atmosphere (Fig. 3) repre- sents an ethylene-production system which does not require the presence of $\mathrm{CO}_{2}$, but rather that the low concentration of $\mathrm{CO}_{2}$ existing in the tissues activates the ethylene-production system. The mechanism by which $\mathrm{CO}_{2}$ modulates the conversion of ACC to ethylene is not understoood. Elucidation of such a regulatory mechanism awaits the successful isolation of this enzyme in cell-free form. Another type of modulation of ethylene production by light is mediated through phytochrome during phototropic curvature and elongation growth; in this case, ethylene production was inhibited by a short exposure to red light, and the inhibition was reversed by far-red irradiation (Goeschl et al. 1967; Kang and Burg 1972; Samimy 1978). In contrast, the light effect described in this paper and others resulted from long exposure to white light and was related to the photosynthetic system. It should be noted that ethylene production rates under optimal $\mathrm{CO}_{2}$ are greater in the light than in darkness (Table 1). Thus light per se is a promoting rather than an inhibiting factor with respect to ethylene production from ACC.

This work was supported by a research grant from the National Science Foundation (PCM-8114933).

\section{References}

Adams, D.O., Yang, S.F. (1979) Ethylene biosynthesis : identification of 1-aminocyclopropane-1-carboxylic acid as an intermediate in the conversion of methionine to ethylene. Proc. Natl. Acad. Sci. USA 76, 170-174

Aharoni, N., Lieberman, M. (1979) Ethylene as a regulator of senescence in tobacco leaf discs. Plant Physiol. 64, 801-804

Craker, L.E., Abeles, F.B., Shropshire, W. (1973) Light-induced ethylene production in sorghum. Plant Physiol. 51, 1082-1083

de Laat, A.M.M., Brandenburg, D.C.C., van Loon, L.C. (1981) The modulation of conversion of 1-aminocyclopropane-1carboxylic acid to ethylene by light. Planta 153, 193-200

Dhawn, K.R., Bassi, P.K., Spencer, M.S. (1981) Effects of carbon dioxide on ethylene production and action in intact sunflower plants. Plant Physiol. 68, 831-834

Gepstein, S., Thimann, K.V. (1980) The effect of light on the production of ethylene from 1-aminocyclopropane-1-carboxylic acid by leaves. Planta 149, 196-199

Gepstein, S., Thimann, K.V. (1981) The role of ethylene in the senescence of oat leaves. Plant Physiol. 68, 349-354

Goeschl, J.D., Pratt, H.K., Bonner, B.A. (1967) An effect of light on the production of ethylene and the growth of the plumular portion of etiolated pea seedlings. Plant Physiol. 43, 1077-1080

Graham, D. (1980) Effects of light on "dark" respiration. In: The biochemistry of plants, vol. 2: Metabolism and respiration, pp. 525-579, Stumpf, P.K., Conn, E.E., eds. Academic Press, New York London 
Grodzinski, B., Boesel, I., Horton, K. (1981) Effect of light and $\mathrm{CO}_{2}$ on the release of ethylene from leaves of Xanthium strumarium. (Abstr.) Plant Physiol. [Suppl.] 67, 272

Johnson, C.M., Stout, P.R., Broyer, T.C., Carlton, A.B. (1957) Comparative chlorine requirements of different plant species. Plant Soil 8, 337-353

Kang, B.G., Burg, S.P. (1972) Relation of phytochrome-enhanced sensitivity to ethylene production. Plant Physiol. 50, 132-135

Lizada, M.C.C., Yang, S.F. (1979) A simple and sensitive assay for 1-aminocyclopropane-1-carboxylic acid. Anal. Biochem. 100, 140-145

Saltveit, M.E., Pharr, D.M. (1980) Light stimulated ethylene production by germinating cucumber seeds. J. Am. Soc. Hort. Sci. 105, 364-367

Samimy, C. (1978) Effect of light on ethylene production and hypocotyl growth of soybean seedlings. Plant Physiol. 61 $772-774$

Wright, S.T.C. (1981) The effect of light and dark periods on the production of ethylene from water-stressed wheat leaves. Planta 153, 172-180

Young, R.E., Romani, R.J., Biale, J.B. (1961) Carbon dioxide effects on fruit respiration. II. Response of avocados, bananas and lemons. Plant Physiol. 37, 416-422

Received 23 March; accepted 20 April 1982 